\title{
Storyboard as a Representation of Urban Architectural Settings
}

\author{
Arif Rahman Wahid ${ }^{1, *}$, and Paramita Atmodiwirjo ${ }^{1}$ \\ ${ }^{1}$ Lecturer, University of Indonesia, Indonesia.
}

\begin{abstract}
Narrative, as one of the closest aspect to human experience, is sometimes overlooked because of its subtlety with everyday life. The study of its representation, narratology, discusses the manner of selling space and time as a series of interconnected events instead of independent occurrences. It offers an interesting view in rethinking architecture, in particular, its representations. In architectural education, dialogue between the two fields will change the way the next generation architecture graduates tell their ideas. Current architecture schools should not be looked as factories that produce only future architects. It is proven by the fact that some, if not most, graduates will have jobs other than professional architects. They may work as set designers, filmmakers, artists, or invent their own field. Architecture schools, at their best, are more about how to ensure the students can perform spatial thinking and expressing their ideas through representation. All of these circumstances lead to the importance of multidisciplinary discourse in architecture education.

This paper aims to explore the potential of storyboarding practice in Basic Design 2 studio as part of architectural education at University of Indonesia. Adopting a narrative element, storyboard in this studio is used to read urban architectural settings and retell everyday life events; scene by scene, unfold in space and time, through different kinds of creative representations. By doing this exercise, the students 'sense of spatial arrangement is developed by their understanding of position and orientation of objects settings. They also learned about how the time works; both in compressed or expanded ways. Decision-making in choosing the key events within the storyboard plays a role in making engaging visuals. In conclusion, storyboarding exercise to represent urban architectural settings will enhance the students 'sensitivity of space, time, and how their ideas are being told by making a rich, multi-layers of narrative.
\end{abstract}

Keywords: Narrative, Representation, Storyboard, Multidisciplinary, Architecture education

\section{The Intriguing World of Narrative Learning in Architecture Education}

"Once upon a time, not too far far away, there is a boy in an architecture studio, a student, sitting in the corner. He reached his smartphone, then start catching monsters with Augmented Reality on the screen, while at the same time prattling with some of his friends about last week's TV serial's season finale. On the table, there are abandoned detail drawings task, and a CAD application opened on the computer. That day is just one of those boring times in the studio for him. Not that he hates it, the boy just does not want to be a professional architect; he planned to make a film after he finishes the course for good."

Let's admit it. Not all architecture school graduates will become architects for their life. They may want to work as filmmakers, artist, set designers, or something else that are entirely different for their career path. Architectural education should not be threatened by this. On the contrary, it means that architectural education can infiltrate many alternative routes other than solely the route of being professional architects. In return, they have to know several skills related to it, like the utilisation of $3 \mathrm{D}$ printing, modelling, CNC cutter, etc. "Even though many skills have to be learnt by an architecture student nowadays, there is a constant need for a future architect to be able to communicate through representation" (Clear, 2014, p.97).

An architecture school, at their best, is more about how to ensure that the students can perform spatial thinking and expressing their ideas through various media that will be delivered to particular audiences. Seeing today's advancement in technology, information overload, and a plethora of media channels used to spread it, now is the time, if not too late, for architectural education to rethink its approach in edifying the students to represent their ideas. Are models, plans, sections, and elevations drawings being all we need to deliver a project?

The infinite possibilities that lie ahead in the future of the students lead to the press of multidisciplinary discourse in architecture education. As the boundaries between disciplines are blurred, multidisciplinary approach provides a way to question traditional architectural education's approach and creating architecture as an integrated spatial design (Clear, 2014). Among many of disciplines, there is narratology, the study of narrative representation, which discusses the manner of telling space and time as a series of interconnected events

* Corresponding author: hello@arifrwahid.com 
instead of independent occurrences. "But the narrative is seen not simply a sequence of events, but renders such sequences, and, through it, 'narrative' itself, as an integral part of human experience" (Koeck, 2013, p.19). "It is something we all engage in, artists and non-artists alike (Abbott, 2002, p.1)”. It is in the vein of our everyday life.

"Here are two views on this question. The first comes from the eminent psychologist Jerome Bruner: "A good story and a well-formed argument are different natural kinds. Both can be used as means for convincing another. Yet what they convince of is fundamentally different: arguments convince one of their truth, stories of their lifelikeness. The one verifies by eventual appeal to procedures for establishing formal and empirical proof. The other establishes not truth but verisimilitude."

Abbott, 2002, p.162

By diving into a narrative area, the knowledge of storytelling will enhance communication skills. In the dialogue within architectural education, for a student, it can be used to engage the audience, whether other students, facilitator, or prospective client to convey his ideas. More importantly, narrative can be used as a new way of rereading a design. "It also might integrate itself with human and cultural memory, and it might be reflexive and performative - in real time or retrospectively" (Spiller, 2014, p.84).

\section{Encounter with the Good Witch of the North}

"No, but I am their friend, although I live in the land of the North. When they saw the Witch of the East was dead the Munchkins sent a swift messenger to me, and I came at once. I am the Witch of the North."

"Oh, gracious!" cried Dorothy. "Are you a real witch?"

"Yes, indeed," answered the little woman. "But I am a good witch, and the people love me. I am not as powerful as the Wicked Witch was who ruled here, or I should have set the people free myself."

(Baum, 2000, p.9)

Just like when Dorothy first met Glinda in the Land of $\mathrm{Oz}$, this is the time for architectural education meets its mentor. Universitas Indonesia gave us the opportunities to explore this belief. Feeling the urge in studying architecture with a multidisciplinary approach, we looked a few steps back and reflected on the purpose of architectural education in Department of Architecture, Faculty of Engineering, Universitas Indonesia. According to its curriculum, the expected learning outcome for their graduates; both in Architecture and Interior Architecture Programme are:

"Able to create architectural design by integrating basic architectural knowledge, applying design and communication skills, applying ability for imagination, creative thinking, innovation and three-dimensional thinking."

"Able to analyse context in which architecture is designed and integrate it through design that responds appropriately to the context."

(Department of Architecture, Faculty of

Engineering Universitas Indonesia, 2017 p.55)

These learning outcomes should be integrated since the beginning of the course to make sure that every student has basic knowledge in architectural design and how to communicate their ideas. In particular, in Basic Design 2, in second-semester studio which we taught, its learning objectives include the ability to produce spatial works that respond to a context through appropriate media and exploration of representation techniques (Faculty of Engineering Universitas Indonesia, 2017).

With one of us has a background in the narrative field, we introduced the students with the practice of storyboarding to help them tell their story. Storyboard is a plan for the visualisation of a story; usually for a film, originates from Disney's artists who pin their individual panels up on the wall to make it easier to be viewed and change things (Glebas, 2009). "By doing one's own storyboards carefully and thoroughly, you know exactly what is going to be done before the actual filming begins" (Hart, 2008, p.3). However, a storyboard is a different form of narrative compared to its planned output media (film, theatre play, etc.). "It is telling a story through a series of pictures" (Glebas, 2009, p.6); even though in the following cases, pictures are not conceived only as a two-dimensional surface that contains images or texts but also as another form of representation.

The storyboarding practice was exercised in a task entitled Urban Walk Project. This brief two-week project involves a group journey to several traditional markets in Jakarta: Pasar Citayam, Kemiri Muka, Lenteng Agung, Pasar Minggu, Cikini Ampiun, Gondangdia, and Petak Sembilan. The selection of those specific places is based on the fact that most of the students had never been to the particular traditional markets. Therefore, the experience will be a novel, unbiased with their preliminary knowledge or memory. In this project, the students are expected to learn how to communicate events and human activities unfold in space and time through different kinds of creative representations of the architectural setting. They also asked to demonstrate appropriate ability in documenting, gathering, and filtering information from urban spaces.

"...the cinematics of a city can be understood without

the linguistic knowledge of units, syntax and grammar. It regards the city as a layered, multifaceted system that is open to interpretation; a poststructuralist sphere that is shaped and understood by more than just functional programme, economic constraints, environmental concerns and social impacts (the measures that normally lie at the fingertips of architects and planners when considering urban interventions). Instead of trying to define a linguistic understanding of urban space, it builds on an existing and habitual system of film language through which we might be able to view, and interpret, urban spaces."

(Koeck, 2013, p.74)

By doing a storyboard, the students perceive the city through a cinematic vision, allowing it to be interpreted in human scale, senses, and feelings. After the preliminary trip to the market, the students are required to develop diverse approaches in reading the market as an urban architectural setting. They have to tell their action plan for the second visit with a purpose of buying some ingredients from the market vendors. Working in pair; the students are maintaining a collaboration process while creating a storyboard which consists of 9-12 frames to depict the field observation. They 
were asked to engage with the environment and observe in detail the events and settings of the trading process between their partner and vendor. Since they are Architecture or Interior Architecture students, three-dimensional creative storyboards are encouraged to be created instead of mere story, on boards.

Glebas (2009) argues that in a live action movie, a storyboard is a visual guide for the director instead of the actors. Since in this project the students take role as both director and actor, the storyboard becomes their guide to undergo the journey. Picking up the Disney's artists idea that the frames in a storyboard could be (re)-arranged easily, it indicates that the journey's sequences could happen in so many ways. The role of the storyboard is to maintain this logical narrative sequence, so it does make sense for its audience (Hart, 2008). Hence, in this paradigm, a storyboard is seen as a planning tool, a representation of one possibility of event that will happen. "[It] is the bridge that allows the tight synchronisation involved in creating live-action actors interacting with virtual monsters, supernatural forces, or moving through complex architectural spaces" (Glebas, 2009, p.48). Treating a storyboard as visual plan could give an adequate direction on what to do or what kind of escapade is there going to be experienced while giving the character enough room for improvisation in the upcoming events.

The Red Shoes and the Winged Monkeys

"Now the charm began to work. The sky was darkened, and a low rumbling sound was heard in the air. There was a rushing of many wings, a great chattering and laughing, and the sun came out of the dark sky to show the Wicked Witch surrounded by a crowd of monkeys, each with a pair of immense and powerful wings on his shoulders."

(Baum, 1900, p.83)

While working with the storyboards, the students are experimenting with many techniques. Since they play the role as author, $\mathrm{h}$, and actor simultaneously, they tend to tell the story of the journey to the market with their corporeal body and senses as the centre of the experience. It runs through their point of view as the walker in the urban space, not as if the God looking from above. The students are reminded to be aware of the minute drama that might happen in the market and involve a bit of exaggeration. This awareness to see ordinary events and brings out qualities to show how significant they are (Glebas, 2009) is genuinely needed in tell a compelling story and architecture as well.

A storyboard often consists of character, setting, and event inside a set of panels. The positioning of the panels will affect the reading experience as they act as an indicator that time or space is being divided (McCloud, 1994). Regarding storyboarding practice in the studio, the shape of the panels is infinite. Because of the three-dimensional aspect of it, the panels could be appeared as rectangular frames, spatial borders between models, or even looked barely panel-less. In accordance to Dorothy's journey which progresses with the appearance of many characters, in this exercise the students created various elements that enrich their storyboard.

Figure 1 shows a relatively basic storyboard form by one of the student pairs. With three panels made more prominent than the others, this storyboard easily emphasise its key events, which is the trading of goods process, marked with the existence of the stall keepers. It also illustrates the insignificant of the characters in that story which can be seen from the colourless figure that represents the protagonist (the student). Whereas the other actors (stall owners) are painted in red, and the goods are kept in their default vibrant colours. This storyboard relies much on photographs to keep its context in the market. However, the setting pictures of the place is also made desaturated. At a glance, the diminished details of the actor might have aimed at highlighting the commodities that were traded, but actually, the act exposes the actors even more. The paradox in the absence of details occurred because of the play in the layer of representations. Other than the main panels consisting of characters, highlighted objects, and backgrounds, there are also texts that work as information of the precise stand location and time of the event.

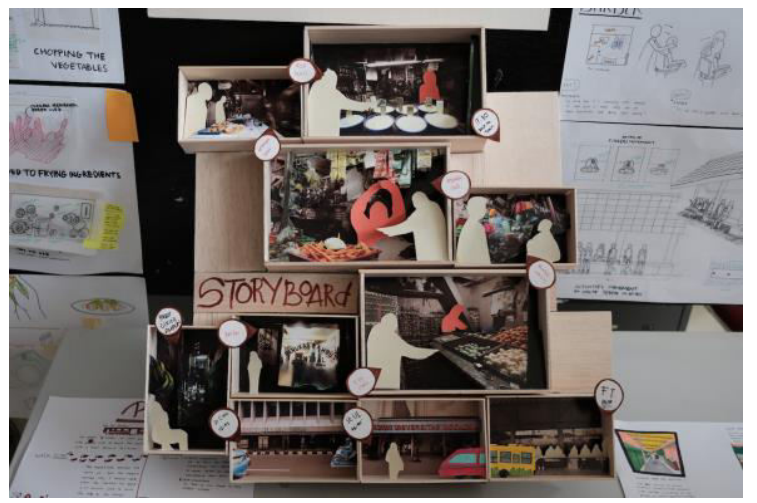

Fig. 1. More Conventional Storyboard with Emphasis on Some Key Panels
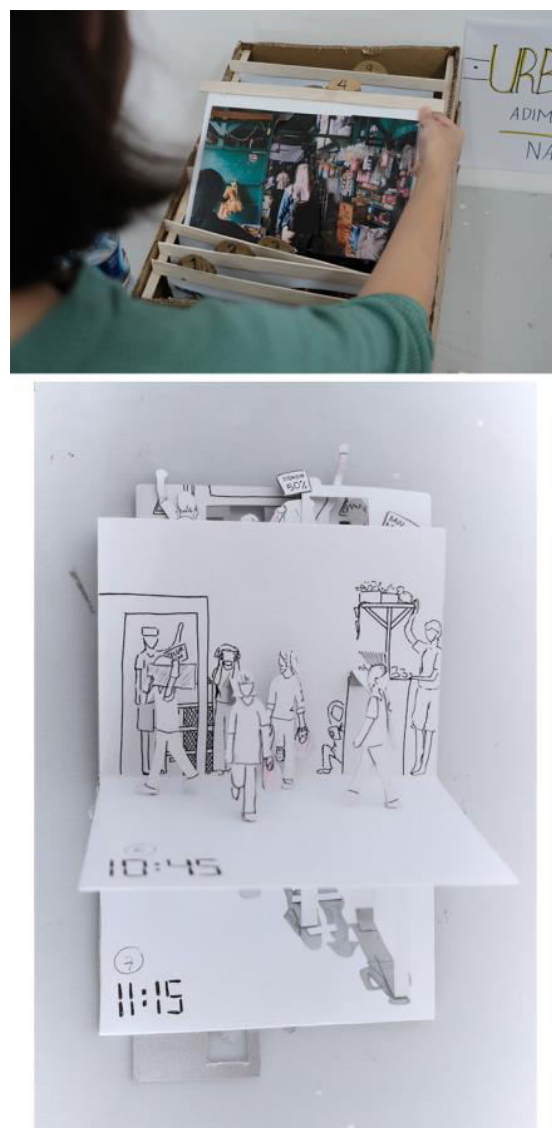

Fig. 2. Layered and Pop Up Book-Style Storyboards. 
Other students made the storyboard with the essence of a book in mind. To comprehend the whole story, the reader is forced to see the pages one by one. In this kind of representations, all scenes are always experienced as the present. When the reader opens a page, the previous page will be the past, and the next one is the future event. As illustrated in Figure 2, the example on the bottom picture made in a pop-up book style to resemble a three-dimensional space. However, here the urban space is read as a combination of people and loose objects in the market such as stalls, openings, and other objects that have a direct interaction with the character. The students leave all ground and far setting in white, so they do not distract the description of the occurred story. The time, in this example, appears explicitly again in every corner of the page with the clock time.

In Figure 3, traditional architectural representation techniques are blended in storyboards in the manner of map and plan connected with panels as spatial references. The interrelation showed by a set of lines or colour codes.

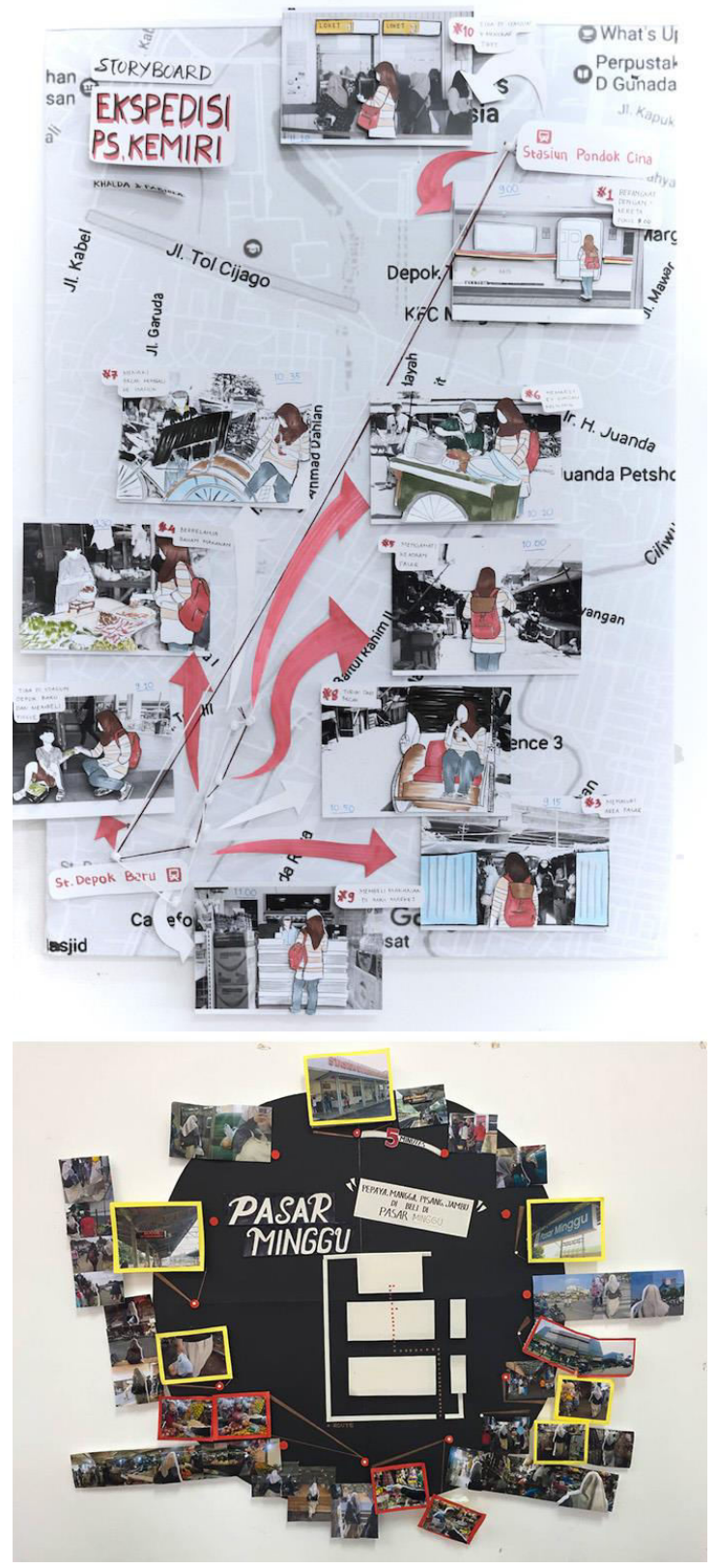

Fig. 3. Storyboards Embedded with Plans
Quite distinctive, the storyboards in Figure 4 do not use fixed borders between panels. Amazingly, the audience still can read the narrative without much hassle. It is our consciousness of narrative that explains how the transition between panels happened. Pictures and the intervals between them create the illusion of time through closure (McCloud, 1994). It has shown cleverly in the use of the train sides. By seeing the surrounding of each front of the train, the audience understands that the train carriage had moved from one station to another. Here, the train acts as the panel and part of the setting as well. The expression of characters in Figure 4 denotes that these students value their character as the main protagonist. The protagonist, printed neatly with a full face and gestures shown to the audience is outstanding from the rest of the setting or the cameos.

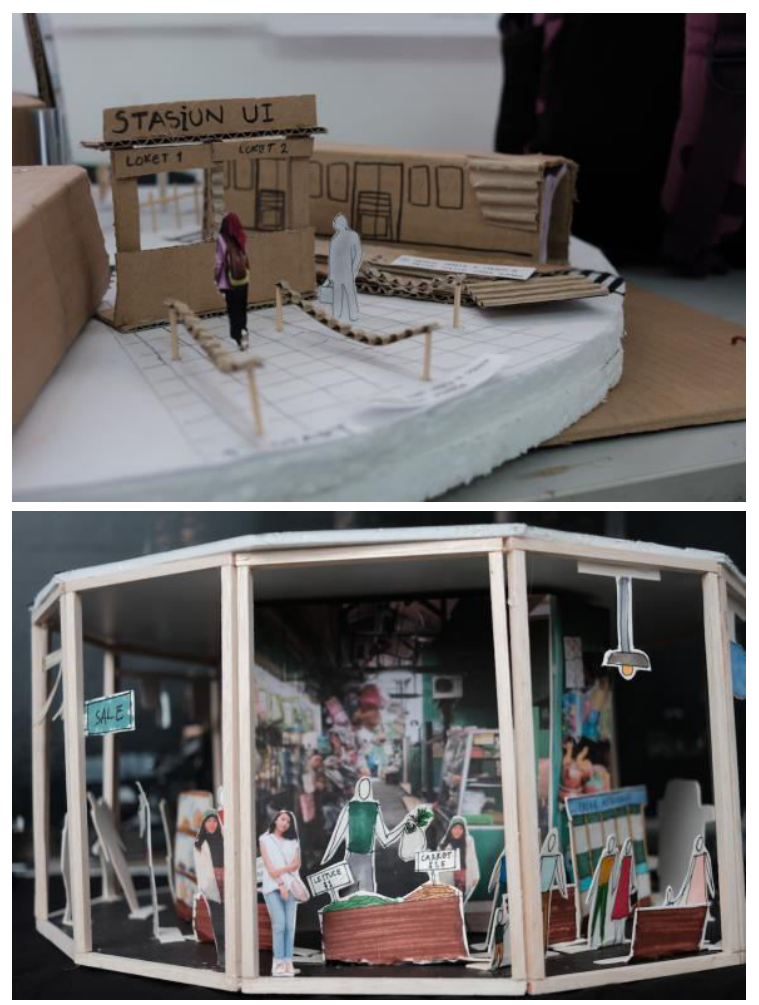

Fig. 4. Blurred Frames, Three-Dimensional Storyboards

Students who worked on the model in Figure 5 represent the market using black colour to distinguish the stalls, actors from the actual space. Characters are shown with red and blue figures; the red indicated the consumer and the blue one marked the shop owner. Solid coloured figures scored the characters base position, while more transparent figures are showing the character's movement. In this model, the story told in a linear way-by the number put on several places-but could be read in a non-linear direction. It is also a noticeable instance of time squeezed in a storyboard. From one sequence, many figures do not represent many people in the market. Instead, they represent the movement of the people which means each figure has its own time. 


\section{When the Two Worlds Collide}

"Hush, my dear," he said. "Don't speak so loud, or you will be overheard--and I should be ruined. I'm supposed to be a Great Wizard."

"And aren't you?" she asked.

"Not a bit of it, my dear; I'm just a common man."

(Baum, 2000, p.105)

From what students had accomplished, there are three key points at least that can be deducted to support the importance of this exploration method. First, the students' sense of spatiality is developed by their discernment of position and orientation of objects in settings. In recreating an urban setting, they consciously observe the surrounding and take note of what placed where and when. The existence of many human beings in the market also become their reference to measure scale, proportion, and rough dimension that make that setting works as a place. This practice challenged the students to record and retell what Koeck (2013, p.73) claimed that "we actually have learned to mentally select and process the flood of moving images to which we are exposed every day".

They also learnt about how the time operates; not only within architecture, but also its representation. By walking in the market, the students are aware of how nimble everything is changing. Specifically, as suggested by McCloud (1994), in a comic-or storyboard in this case-we perceive the time spatially. In other words, space and time are merged. From several cases mentioned above, each panel of the storyboard displayed how the time can be compressed or expanded. For instance, in Figure 1, in which the protagonist buys vegetables, and the vendor prepares to pack them as well, or the double actors and vendors that exist in Figure 5. In a real world, the actual sequence would be somebody asks the shop owner to buy vegetables, only then the seller prepares it. And the duplication of characters in Figure 5 obviously shows their movement throughout the time. Nevertheless, our mind knows the order of the event. As Abbott (2002) suggested, the storyboards as a narrative form, functioned to be a mechanism for expressing our awareness of time.

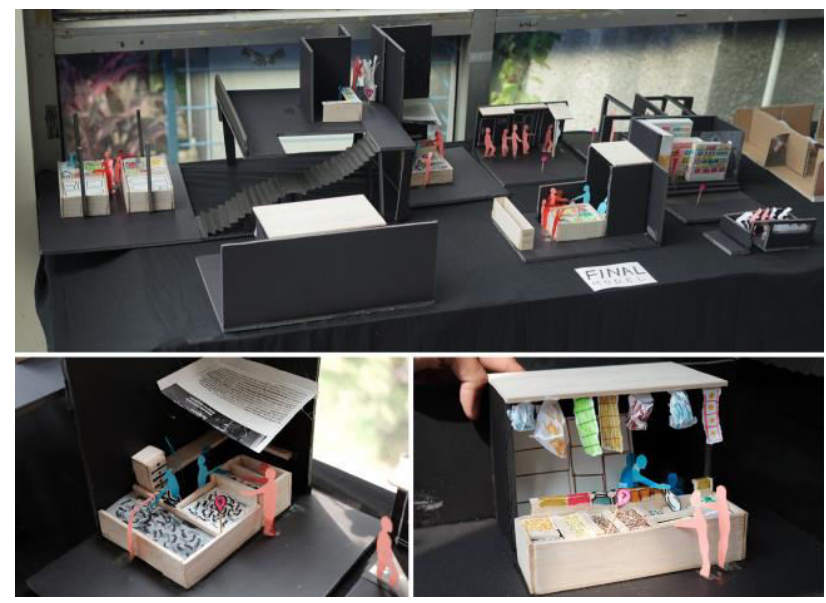

Fig. 5. Storyboarding with Detailed Architecture Model

Creative thinking and decision making are the third important aspect addressed in this exercise. It includes the planning of the structure, composition, and overall look of the storyboard. Although there is flexibility to arrange the scenes back and forth in a storyboard, at the same time it forces the students to have the fixed order of the panels. Chosen events that appeared in the panels must indicate the critical stage of the story. Also, they should be able to hook the audience by making engaging visuals through various methods of representations. Creative thinking plays a role in deciding what format the storyboard should be, depending on who the audience is. In a real movie pitch, a storyboard is widely used as a tool to explain the whole story visually and convince the stakeholders. Likewise, in architecture crit, the students need to articulate their ideas and designs, in a logical narrative using their choice of media (models, drawings, diagrams, etc.) to the reviewer as the audience. Hence, the storyboarding practice could help the students to make captivating presentations via its narrative structure.

\section{The Aftermath}

"My greatest wish now," she added, "is to get back to Kansas, for Aunt Em will surely think something dreadful has happened to me, and that will make her put on mourning; and unless the crops are better this year than they were last, I am sure Uncle Henry cannot afford it."

Glinda leaned forward and kissed the sweet, upturned face of the loving little girl.

"Bless your dear heart," she said, "I am sure I can tell you of a way to get back to Kansas."

(Baum, 2000, p.144)

Now we should return to the root of this discussion, the architectural education. We would argue that multidisciplinary learning in architectural education indeed broaden the perspective on architecture. Storyboard, borrowed from narratology and filmmaking provides an exciting view of seeing architectural representation. By using that practice, the students are given the task to plan their journey to an urban architectural setting. Along the project, the practice of storyboarding advanced the students' sensitivity of space, time, and how their ideas are being told by making a rich, multi-layers narrative. Moreover, in the subsequent studios, the mixture between well-formed argument and a vast amount of lifelikeness storytelling through various methods of representations can help the students convince their audience and create an engaging design.

As the curtains are going down, we may conclude that the use of storyboard does affect the way representation is made in architectural education. Probably not all sets of architectural drawings are required for all types of tasks. There is no doubt that models, plans, sections, elevations, or perspectives drawings are needed at some point in the process. But at certain times, using a storyboard is more relevant in showing students' creative thinking with the point of view of the protagonist, the walker in the urban spaces. However, the practice of storyboarding cannot be taken as the elixir that brought by the hero in Campbell's hero's journey structure. Rather, we can put it as one of the thousands of the hero's faces. Storyboard is only one approach that offers an alternative representation technique which will help the learning process in architecture education. Finally, there is no happily ever after as the real world is a never-ending field of conflicts. It all depends on the students' shoulder as the future architects, which will be the right tools for the right jobs at the right time. Fin. 


\section{Acknowledgement}

The photos included in this paper are student works of Urban Walk Project in Basic Design 2 Studio, class of 2016 from Architecture and Interior Architecture programme at Universitas Indonesia.

\section{References}

Abbott, H. P. (2002). The Cambridge introduction to narrative. Cambridge: Cambridge University Press.

Baum, L. F. (2000). The Wonderful Wizard of Oz. Retrieved from www.ebooksdirectory.com/details.php?ebook=1254.

Clear, N. (2014). Convergence: Architecture as intregrated spatial design in Spiller, N., \& Clear, N. (Eds.). (2014). Educating architects: how tomorrow's practitioners will learn today. New York: Thames \& Hudson.

Faculty of Engineering, Universitas Indonesia. (2017). Universitas Indonesia, Faculty of Engineering Academic Guidebook: Architecure Department (2017 Edition). Retrieved from http://eng.ui.ac.id/wpcontent/uploads/BUKU-ARSITEK-INGGRIS.pdf

Glebas, F. (2009). Directing the story: professional storytelling and storyboarding techniques for live action and animation. China: Elsevier/Focal Press.

Hart, J. (2008). The art of the storyboard: a filmmaker's introduction. Boston: Elsevier/Focal Press.

Koeck, R. (2013). Cine-scapes: cinematic spaces in architecture and cities. New York: Routledge.

McCloud, S. (1994). Understanding comics: the invisible art. New York: HarperPerennial.

Spiller, N. The architectural mixing desk of the surrealist city in Spiller, N., \& Clear, N. (Eds.). (2014). Educating architects: how tomorrow's practitioners will learn today. New York: Thames \& Hudson. 